\title{
Prognostic factors of afatinib as a first-line therapy for advanced EGFR mutation-positive lung adenocarcinoma: a real-world, large cohort study
}

\author{
Sheng-Kai Liang ${ }^{1,2}$, Meng-Rui Lee ${ }^{1}$, Wei-Yu Liao ${ }^{3}$, Chao-Chi $\mathrm{Ho}^{3}$, Jen-Chung Ko ${ }^{1}$ \\ and Jin-Yuan Shih ${ }^{3}$ \\ ${ }^{1}$ Department of Internal Medicine, National Taiwan University Hospital Hsinchu Branch, Hsinchu, Taiwan
${ }^{2}$ Institute of Biotechnology, National Tsing Hua University, Hsinchu, Taiwan
${ }^{3}$ Department of Internal Medicine, National Taiwan University Hospital and College of Medicine, National Taiwan University,
Taipei, Taiwan \\ Correspondence to: Jin-Yuan Shih, email: jyshih@ntu.edu.tw \\ Keywords: afatinib; EGFR mutation-positive lung adenocarcinoma; prognostic factor; first-line therapy; real-world study \\ Received: December 26, $2017 \quad$ Accepted: April 07, $2018 \quad$ Published: May 04, 2018 \\ Copyright: Liang et al. This is an open-access article distributed under the terms of the Creative Commons Attribution License 3.0 \\ (CC BY 3.0), which permits unrestricted use, distribution, and reproduction in any medium, provided the original author and source \\ are credited.
}

\section{ABSTRACT}

Lung cancer remains the primary cause of cancer-related mortality worldwide. Several treatment modalities are available for lung cancer, including surgery, radiation, and chemotherapy. Among the chemotherapeutics available, afatinib has been shown to be effective for those with epidermal growth factor receptor (EGFR) mutation-positive lung adenocarcinoma. Herein, we analyzed the factors affecting the prognosis of patients who received afatinib as a first-line therapy for advanced EGFR mutation-positive lung adenocarcinoma in the real-world setting. Patients who received afatinib as a first-line therapy and were reimbursed by the National Health Insurance were recruited in this study. Data on patient characteristics and treatment courses were collected. In total, 259 patients were enrolled (median follow-up, 22.0 months). Of them, $82(31.7 \%)$ were identified to have brain metastases at baseline, which were associated with poor Eastern Cooperative Oncology Group performance status, high incidence of central nervous system progression, and short overall survival. However, the results of our analysis showed that overall survival was not affected by reductions in the afatinib dosage or any upfront local treatments for brain tumors. Multivariate analyses showed that brain metastases at diagnosis and treatment response to afatinib are two important prognostic factors for the overall survival of patients with EGFR mutation-positive lung adenocarcinoma.

\section{INTRODUCTION}

Lung cancer remains the leading cause of mortality among all malignant diseases worldwide. Despite advances in precision medicine in the past decade, the 5 -year overall survival of patients with advanced lung cancer is less than $10 \%[1,2]$. Several favorable prognostic factors had been discussed in patients with advanced nonsmall cell lung cancer (NSCLC), including early TNM stage for tumors [1], good performance status (PS) on the
Karnofsky Performance Index or the Eastern Cooperative Oncology Group (ECOG) scale [3, 4], female sex [5], young age [3, 4], and non-neuroendocrine characteristics in histology [6].

Mutations in the epidermal growth factor receptor (EGFR) kinase domain of lung adenocarcinoma have been viewed as the most reproducible predictive factor for susceptibility to first-generation EGFR tyrosine kinase inhibitors (TKIs) [7]. Afatinib is an irreversible ErbB family blocker and a second-generation EGFR-TKI, 
and its efficacy as first-line treatment for patients with advanced EGFR mutation-positive lung adenocarcinoma has subsequently been proven [8-10].

Up to $20 \%$ of patients with NSCLC present with central nervous system (CNS) metastases at the time of first diagnosis $[11,12]$. The use of any first- or secondgeneration EGFR-TKIs alone for the treatment of brain metastases in patients with EGFR mutant-positive lung adenocarcinoma showed a favorable cerebral response rate of $>50 \%$ [13-16]. The efficacy of EGFR-TKIs for controlling brain metastases has been shown to be similar to that of surgical resection, stereotactic radiosurgery (SRS), or whole-brain radiotherapy (WBRT) $[17,18]$.

In our previous study [19], brain metastases were found to be a significant prognostic factor for progressionfree survival (PFS) in patients with EGFR mutationpositive lung adenocarcinoma receiving afatinib as firstline treatment. Well-designed, randomized controlled trials can prove the efficacy of the study drugs in terms of response rate and PFS, but a single-center study can demonstrate the overall survival (OS) benefit of the drug in the study population. Prognostic factors can be studied in real-world patient settings. As such, we extended our previous research [19] and analyzed a real-world cohort of patients treated with first-line afatinib. Further, we investigated the prognostic factors in this specific population.

\section{RESULTS}

\section{Demographics and clinical variables of the study}

This is an extended study from our previous cohort research, and part of the results had been published [19]. We retrospectively recruited this study cohort from the Taiwan National Health Insurance approved list of afatinib applicants from May 2014 to June 2017 at the National Taiwan University Hospital, a tertiary medical center in Taiwan. A total of 282 patients were screened, and 259 met the inclusion criteria of advanced EGFR mutationpositive lung adenocarcinoma with afatinib as a firstline treatment (Figure 1). The patients' median age was 62 (range, 28-87) years. A total of 157 patients (60.6\%) were women, and $187(72.2 \%)$ were never smokers (Table 1). Most patients had relatively good PS, and only 19 patients $(7.4 \%)$ had an ECOG performance score of $\geq$ 2. The enrolled patients were divided into three groups according to their EGFR mutation status as defined in the previous study: Group 1, "classical" mutation; Group 2, complex mutation with classical mutation; and Group 3, rare mutation with or without complex mutation. Majority of the patients belonged to Group $1(\mathrm{n}=207,79.9 \%)$. A total of $151(58.3 \%)$ patients had exon 19 deletion, while $53(20.5 \%)$ had p.L858R mutation.

Approximately 181 patients $(69.9 \%)$ received $40 \mathrm{mg}$ afatinib as initial dose. Of them, $97(53.7 \%)$ tolerated the
$40 \mathrm{mg}$ dose through the first 6 months. We also determined the treatment responses to afatinib through imaging studies and by reviewing patients' medical records (Table 2). A total of $180(69.5 \%), 60(23.2 \%)$, and $19(7.3 \%)$ patients had partial response, stable disease, and progressive disease, respectively.

After a median follow-up duration of 22 months, the median PFS of the total patient population was 12.8 (95.0\% confidence interval [CI]: 11.1-14.5) months, and the median OS was 36.7 months. Concurrently, PFS (median: 13.2 [95.0\% CI: 11.2-15.1] vs. 12.5 [95.0\% CI: 9.7-15.3] months, respectively; $P=0.865)$ and OS (median: 36.7 [95.0\% CI: 32.1-41.2] months vs. not reached, respectively; $P=0.992$ ) was not significantly different between patients who received $40 \mathrm{mg}$ and $<40$ $\mathrm{mg}$ afatinib in the first 6 months of treatment (Figure 2). However, patients with a partial response after afatinib treatment had longer OS compared to those with stable or progressive disease (both groups did not reach median duration, $P<0.001)$.

\section{Brain metastases as a poor prognostic factor}

Of the 259 eligible patients, $82(31.7 \%)$ were identified to have brain metastases at baseline. Patients were further subdivided into two subgroups according to the presence or absence of brain metastases at the initial clinical staging workup. No significant differences in various clinical characteristics, including age, smoking status, and EGFR mutation patterns, were observed between the two subgroups. Patients with brain metastases had poorer ECOG PS compared with those without brain metastases $(P<0.001)$ (Table 1$)$. However, the initial dose preference (40 $\mathrm{mg}$ or $<40 \mathrm{mg}$ of afatinib) and using 40 $\mathrm{mg}$ dosage in the entire first 6 months were not different between the two groups $(P>0.05)$ (Table 2). Meanwhile, patients with initial brain metastases had significantly higher incidence of central nervous system (CNS) progression $(P<0.001)$ (Table 2$)$ and a shorter OS than those without brain metastases (median: 33.8 months vs. not reached, respectively; $P=0.005$; hazard ratio [HR]: 2.03; 95.0\% CI: 1.23-3.35) (Figure 3).

Those 82 patients with baseline brain metastases were subdivided into two groups according to the dose of afatinib during the first 6 months of treatment $(40 \mathrm{mg}$ versus $<40 \mathrm{mg}$ ). There were no significant differences in gender, body mass index (BMI), body surface area (BSA), and ECOG PS between the two groups. Furthermore, the dose of afatinib during the first 6 months of treatment (40 $\mathrm{mg}$ versus $<40 \mathrm{mg}$ ) did not make differences in clinical outcomes, including response rate $(62.2 \%$ vs. $64.9 \%$ respectively; $P=0.805$ ), PFS (median: 11.3 [95.0\% CI: 8.0-14.6] vs. 9.0 [95.0\% CI: 6.9-11.1] months, respectively; $P=0.766$ ) and OS (median: $33.2[95.0 \%$ CI: 15.6-50.7] months vs. not reached, respectively; $P=$ 0.352) (Supplementary Table 1). 


\section{Treatment modalities in patients with brain metastases}

Eighty-two patients $(31.7 \%)$ presented with brain metastases at the time of initial diagnosis (Figure 1), and $6(7.3 \%)$ of them presented with leptomeningeal carcinomatosis. To determine the clinical factors affecting survival, we subdivided these 82 patients according to whether or not they received upfront local treatment to brain lesions (Table 3). In terms of clinical characteristics, no significant differences in age, smoking status, and $E G F R$ mutation patterns were found between these two groups. Patients with brain metastases who initially presented with poor PS, neurological symptoms, $>3 \mathrm{~cm}$ brain tumor, or intracranial hemorrhage tended to receive upfront local treatment.

Competing risk regression analysis revealed that brain metastasis at initial diagnosis was associated with high risk for CNS progression (subhazard ratio: 3.34; 95.0\% CI: $1.68-6.67 ; P=0.001$ ) (Figure 4). However, no difference in cumulative incidence of CNS progression (subhazard ratio: $1.16 ; 95.0 \% \mathrm{CI}: 0.54-2.50 ; P=0.70$ ) (Figure 4) and in OS (median 36.7 vs. 19.5 months, respectively; (HR: 0.73; 95.0\% CI: 0.34-1.56; $P=0.409$ ) (Figure 5) was noted between patients with initial brain metastases who did and did not receive upfront local treatments.

No standard treatment modalities for neurologically asymptomatic brain metastases in patients with EGFR mutation have been established. We analyzed those neurologically asymptomatic patients in our study $(\mathrm{n}=$ $54)$ who received any upfront local treatment $(n=16)$ and found that such treatment had no significant OS benefit compared with those without upfront local treatment (median OS: 33.1 vs. 19.5 months, respectively; $P=$ 0.728) (HR: 0.84; 95.0\% CI: 0.31-2.28).

\section{Univariate and multivariate analyses of overall survival}

We used univariate and multivariate analyses to determine the influence of clinical factors on OS of afatinib-treated patients in our real-world cohort study. The results of multivariate analyses showed that clinical variables, including sex, smoking status, EGFR mutation status, and $40 \mathrm{mg}$ or $<40 \mathrm{mg}$ of afatinib dose in the first 6 months, were not associated with OS, and the most significant prognostic factors influencing OS were existence of brain metastases and treatment responses at initial evaluation (Table 4).

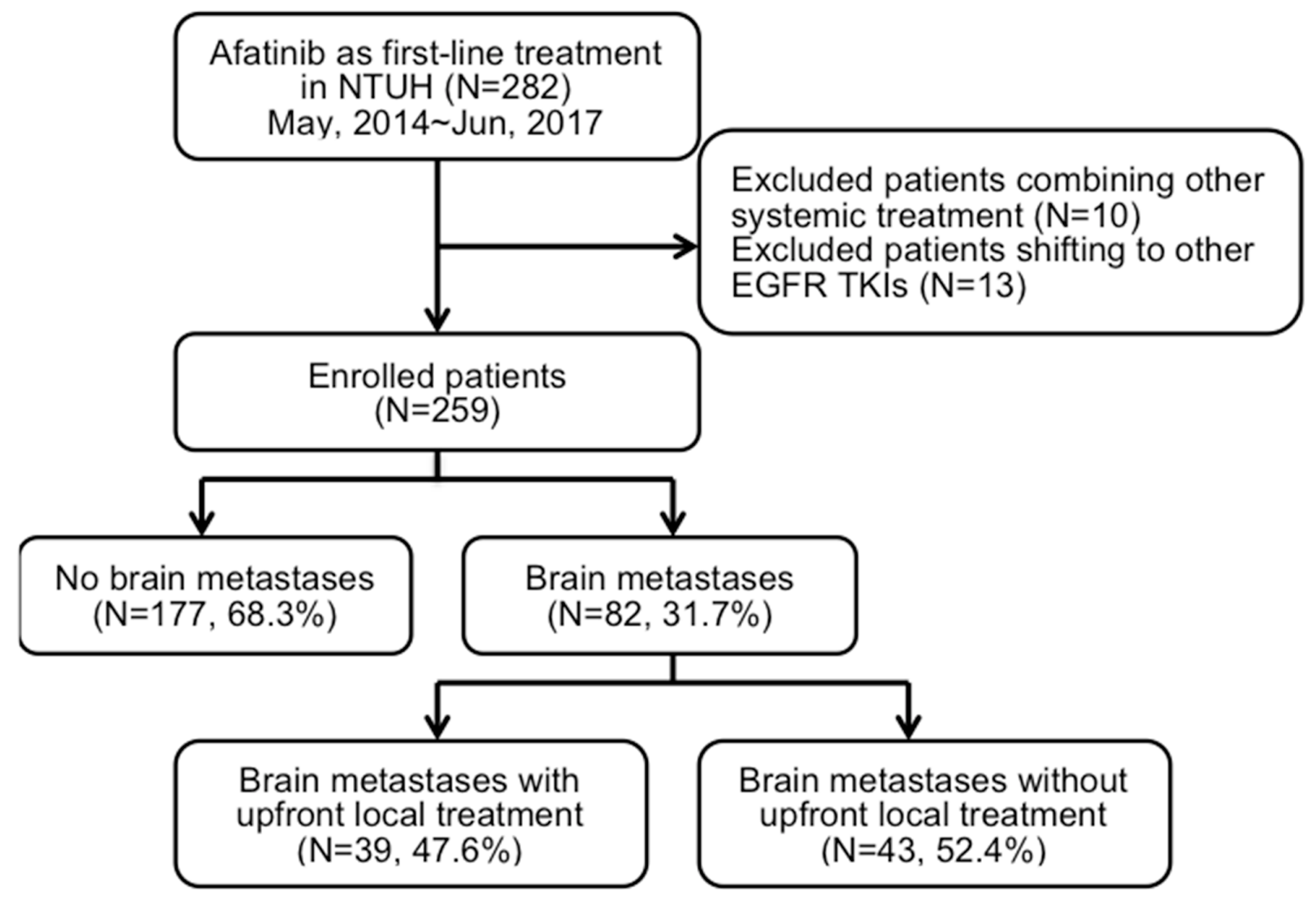

Figure 1: Flow chart of patient recruitment. 
Table 1: Clinical characteristics and comparison of patients receiving afatinib according to brain metastases

\begin{tabular}{|c|c|c|c|c|}
\hline \multirow[t]{3}{*}{ Characteristic } & \multicolumn{3}{|c|}{ Patients receiving afatinib as first-line treatment } & \multirow[t]{3}{*}{$P$-value } \\
\hline & All & With BM & Without BM & \\
\hline & $(n=259)$ & $(n=82)$ & $(n=177)$ & \\
\hline Age (years), median (range) & $62(28-87)$ & $61(31-82)$ & $62(28-87)$ & \\
\hline Sex, $n(\%)$ & & & & 0.724 \\
\hline M & $102(39.4)$ & $31(37.8)$ & $71(40.1)$ & \\
\hline $\mathrm{F}$ & $157(60.6)$ & $51(52.2)$ & $106(59.9)$ & \\
\hline Smoking status, $n(\%)$ & & & & 0.846 \\
\hline Never smoked & $187(72.2)$ & $61(74.4)$ & $126(71.2)$ & \\
\hline Ex-smoker ${ }^{\mathrm{a}}$ & $26(10.0)$ & $8(9.8)$ & $18(10.2)$ & \\
\hline Current smoker & $46(17.8)$ & $13(15.9)$ & $33(18.6)$ & \\
\hline Baseline ECOG PS, $n(\%)$ & & & & $<0.001^{*}$ \\
\hline 0 & $77(29.7)$ & $21(25.6)$ & $56(31.6)$ & \\
\hline 1 & $163(62.9)$ & $46(56.1)$ & $117(66.1)$ & \\
\hline $2-4$ & $19(7.4)$ & $15(18.3)$ & $4(2.3)$ & \\
\hline EGFR mutation status, $n(\%)$ & & & & 0.895 \\
\hline Group 1 (Classical mutation[s]) & $207(79.9)$ & $65(79.3)$ & $142(80.2)$ & \\
\hline 19DEL & $151(58.3)$ & $49(59.8)$ & $102(57.6)$ & \\
\hline p.L858R & $53(20.5)$ & $14(17.1)$ & $39(22.0)$ & \\
\hline p.L858R and 19DEL & $3(1.2)$ & $2(2.4)$ & $1(0.6)$ & \\
\hline $\begin{array}{l}\text { Group } 2 \text { (Complex mutation with } \\
\text { classical mutation) }\end{array}$ & $11(4.2)$ & $3(3.7)$ & $8(4.5)$ & \\
\hline p.L858R and p.T790M & $5(1.9)$ & $2(2.4)$ & $3(1.7)$ & \\
\hline Other & $6(2.3)$ & $1(1.3)$ & $5(2.8)$ & \\
\hline $\begin{array}{l}\text { Group } 3 \text { (Rare mutation with or } \\
\text { without complex mutation) }\end{array}$ & $41(15.8)$ & $14(17.1)$ & $27(15.3)$ & \\
\hline p.L861Q & $14(5.4)$ & $4(4.9)$ & $10(5.6)$ & \\
\hline p.G719X & $11(4.2)$ & $4(4.9)$ & $7(4.0)$ & \\
\hline $20-I N S$ & $3(1.2)$ & $1(1.2)$ & $2(1.1)$ & \\
\hline p.G719A and p.T790M/Others & $13(5.0)$ & $5(6.1)$ & $8(4.5)$ & \\
\hline
\end{tabular}

${ }^{*} P<0.05$.

${ }^{\mathrm{a}}$ Ceased smoking $>1$ year before diagnosis.

BM, brain metastases; cStage, clinical stage; DEL, deletion; ECOG, Eastern Cooperative Oncology Group; F, female; INS, insertion; EGFR, epidermal growth factor receptor; M, male; PS, performance status; SD, standard deviation.

\section{DISCUSSION}

The median PFS and OS of patients with EGFR mutations were 12.8 and 36.7 months, respectively. The absence of brain metastases and response to afatinib treatment was associated with better OS. Clinically, ECOG PS status is considered an important prognostic factor for
OS of patients with $E G F R$ mutation-positive lung cancer [4]. In our study, the enrolled patients without brain metastases had a relatively good ECOG PS compared with those with brain metastases, but PS status in afatinib as first-line treatment in patients with EGFR mutationpositive lung adenocarcinoma did not yield a difference in OS after multivariate analyses. 


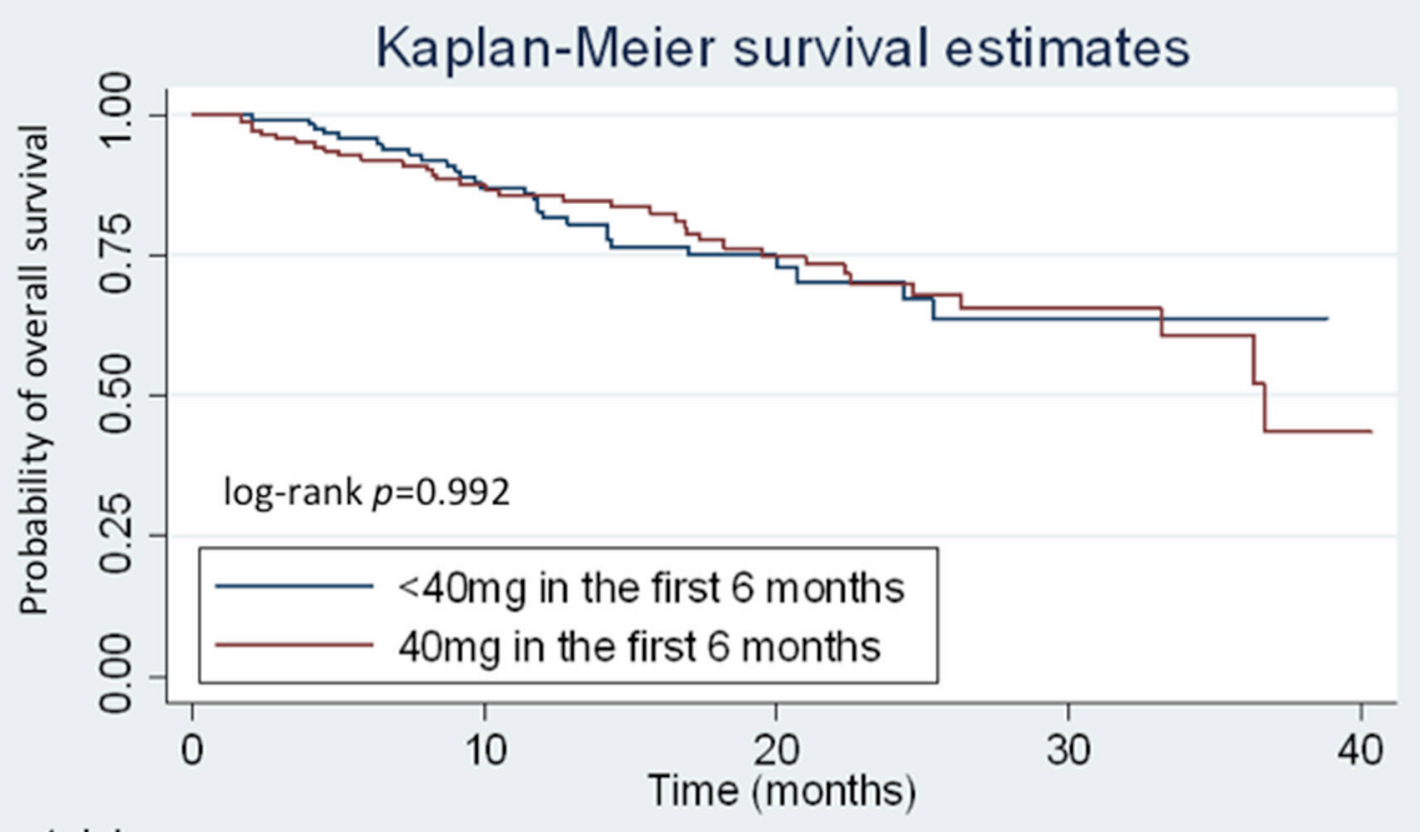

Number at risk

$<40 \mathrm{mg} 120$

40mg 139

85

94

33

51

11

17

0

1

Figure 2: Kaplan-Meier curves for overall survival (OS) according to the treatment dose of afatinib. Patients receiving $40 \mathrm{mg}$ and $<40 \mathrm{mg}$ of afatinib during the first 6 months are represented by the red and blue lines, respectively.

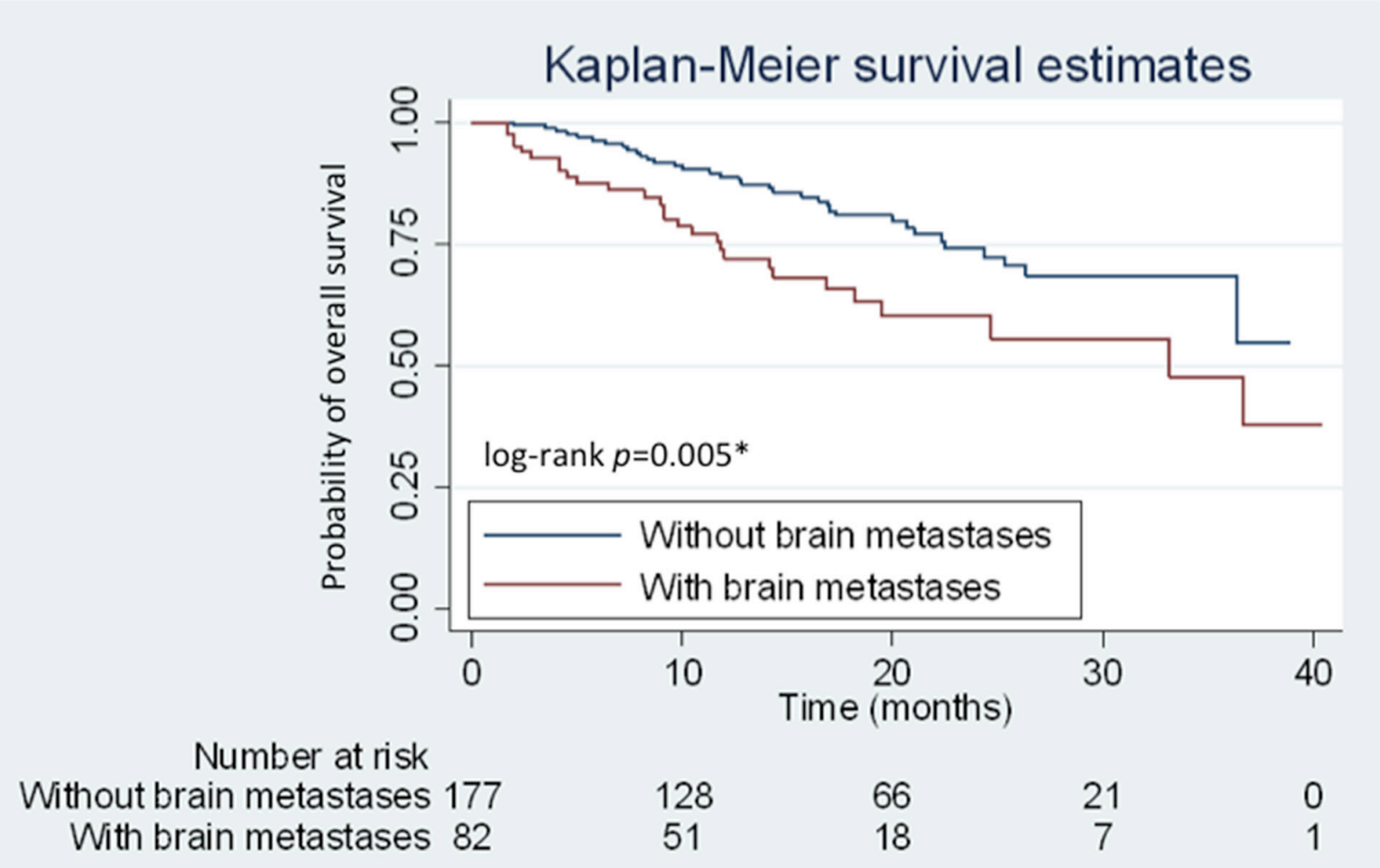

Figure 3: Kaplan-Meier curves for overall survival (OS) of patients with and without brain metastases. Patients with and without brain metastases are represented by red and blue lines, respectively. 


\section{Competing-risks regression}

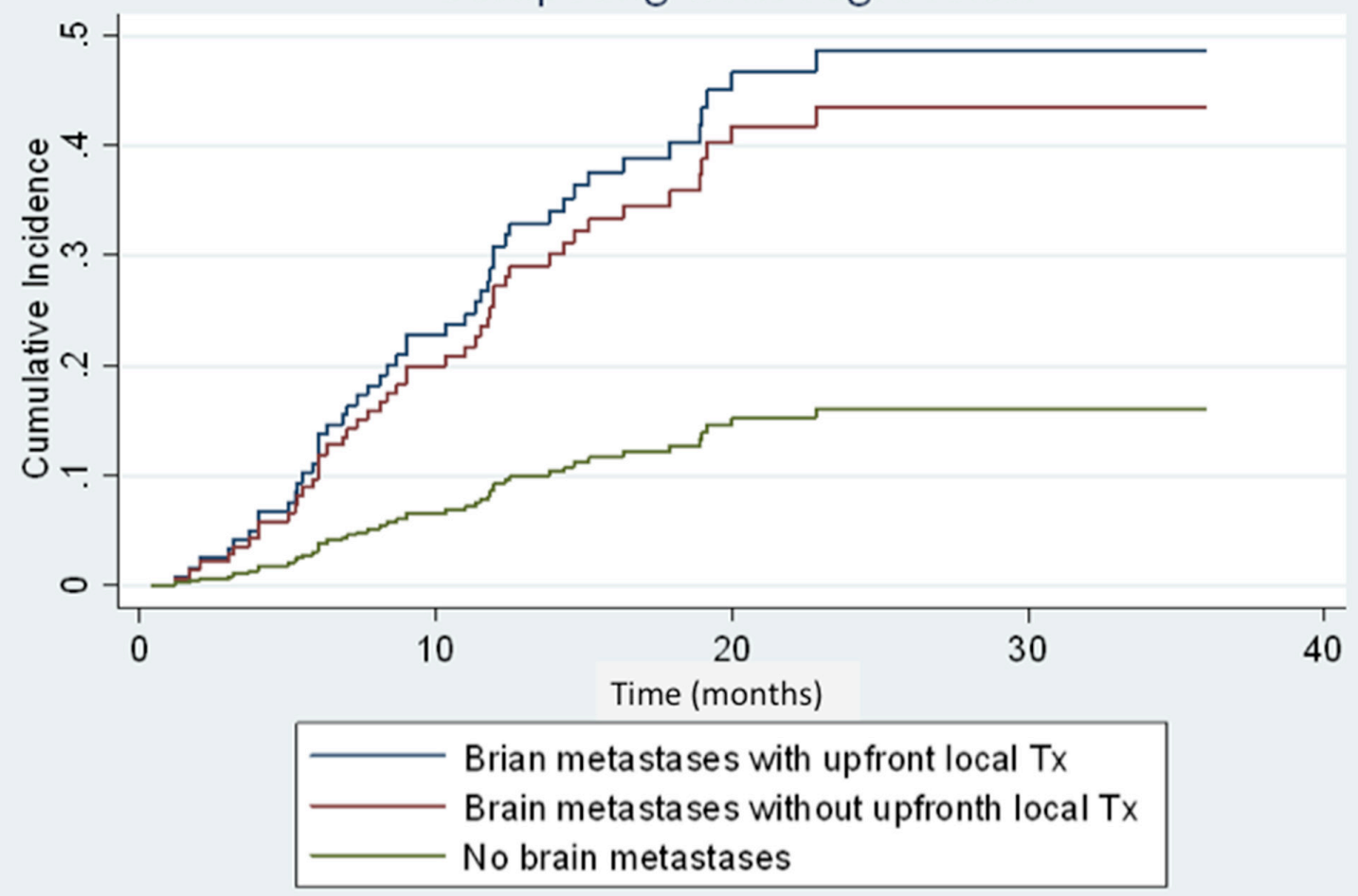

Figure 4: Cumulative incidence curves of central nervous system (CNS) progression of patients with brain metastases with/without upfront local treatment and patients without brain metastases at diagnosis. Patients with brain metastases with/without upfront local treatment and patients without brain metastases are represented by the blue, red, and green lines, respectively.

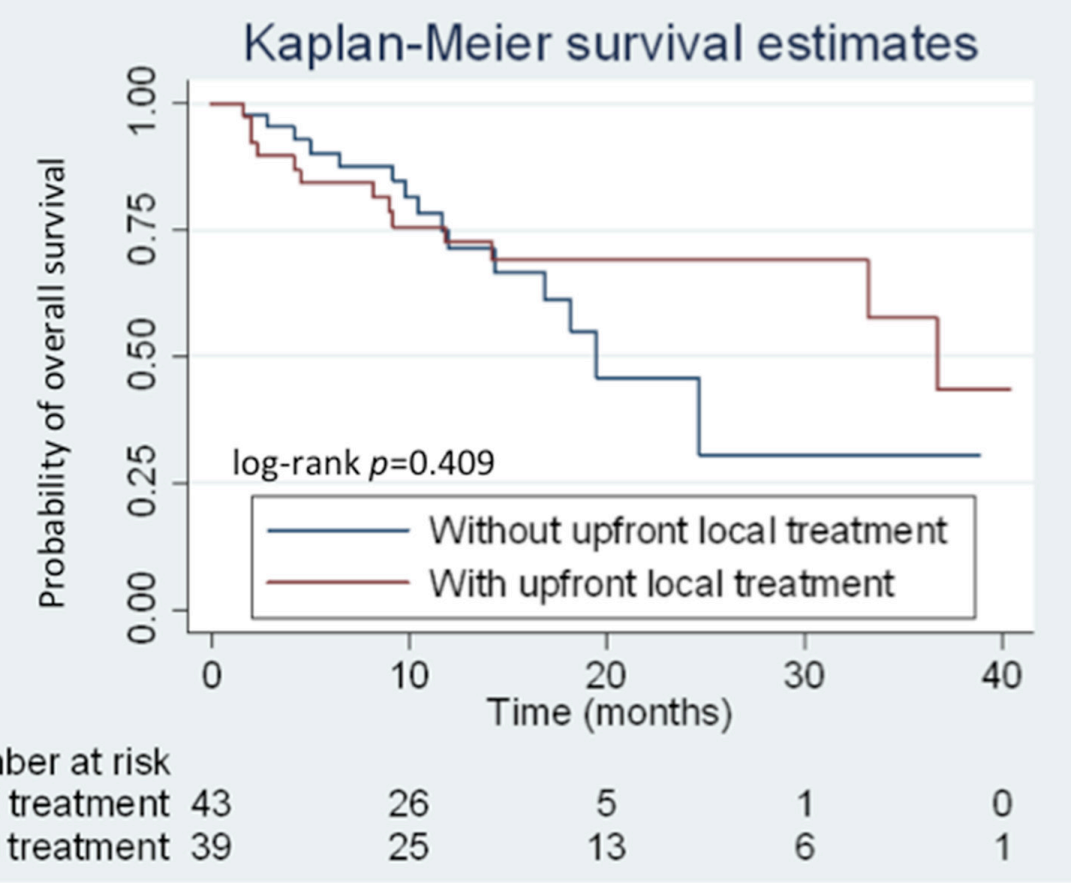

Figure 5: Kaplan-Meier curves for overall survival (OS) of patients with and without upfront local treatment. Patients with and without upfront local treatment are represented by the red and blue lines, respectively. 
Table 2: Comparison of afatinib dose and effects according to brain metastases

\begin{tabular}{|c|c|c|c|c|}
\hline \multirow[t]{3}{*}{ Variable } & \multicolumn{3}{|c|}{ Patients with afatinib as first-line treatment } & \multirow[t]{3}{*}{$P$-value } \\
\hline & All & With BM & Without BM & \\
\hline & $(n=259)$ & $(n=82)$ & $(n=177)$ & \\
\hline Initial dose with $40 \mathrm{mg}, n(\%)$ & $181(69.9)$ & $58(70.7)$ & $123(69.5)$ & 0.84 \\
\hline $40 \mathrm{mg}$ in the first 6 months, $n(\%)$ & $139(53.7)$ & $45(54.9)$ & $94(53.1)$ & 0.79 \\
\hline Initial tumor response to afatinib treatment, $n(\%)$ & & & & 0.211 \\
\hline PR & $180(69.5)$ & $52(63.4)$ & $128(72.3)$ & \\
\hline SD & $60(23.2)$ & $21(25.6)$ & $39(22.0)$ & \\
\hline PD & $19(7.3)$ & $9(11.0)$ & $10(5.6)$ & \\
\hline Disease progression events after treatment, $n$ & $148(57.1)$ & $54(65.9)$ & $94(53.1)$ & 0.054 \\
\hline CNS progression, $n(\%)$ & $47(18.1)$ & $27(32.9)$ & $20(11.3)$ & $<0.001^{*}$ \\
\hline Non-CNS progression, $n(\%)$ & $101(39.0)$ & $27(32.9)$ & $74(41.8)$ & \\
\hline
\end{tabular}

BM, brain metastases; CNS, central nervous system; PD, progressive disease; PR, partial response; SD, stable disease.

Table 3: Characteristics of patients with brain metastases (BMs) who did and did not receive upfront local treatment for brain lesions

\begin{tabular}{|c|c|c|c|}
\hline \multirow[t]{2}{*}{ Characteristic } & $\begin{array}{l}\text { Patients with BMs with } \\
\text { upfront local treatment }\end{array}$ & $\begin{array}{l}\text { Patients with BMs without } \\
\text { upfront local treatment }\end{array}$ & $P$-value \\
\hline & $(n=39)$ & $(n=43)$ & \\
\hline Sex, $n(\%)$ & & & 0.567 \\
\hline M & $16(41.0)$ & $15(34.9)$ & \\
\hline $\mathrm{F}$ & $23(59.0)$ & $28(65.1)$ & \\
\hline Smoking status, $n(\%)$ & & & 0.521 \\
\hline Never smoked & $27(69.2)$ & $34(79.1)$ & \\
\hline Ex-smoker ${ }^{\mathrm{a}}$ & $4(10.3)$ & $4(9.3)$ & \\
\hline Current smoker & $8(20.5)$ & $5(11.6)$ & \\
\hline ECOG PS, $n(\%)$ & & & $<0.001^{*}$ \\
\hline 0 & $5(12.8)$ & $16(37.1)$ & \\
\hline 1 & $21(53.8)$ & $25(58.1)$ & \\
\hline $2-4$ & $13(33.4)$ & $2(4.7)$ & \\
\hline Presence of neurological symptoms, $n(\%)$ & $23(59.0)$ & $5(11.6)$ & $<0.001^{*}$ \\
\hline \multicolumn{4}{|l|}{ Patterns of BMs, $n(\%)$} \\
\hline Single metastasis & $14(35.9)$ & $8(18.6)$ & 0.078 \\
\hline The largest tumor $>3 \mathrm{~cm}$ in diameter & $12(30.8)$ & 0 & $<0.001^{*}$ \\
\hline Intracranial hemorrhage & $4(10.3)$ & 0 & $<0.001^{*}$ \\
\hline Leptomeningeal carcinomatosis & $1(2.6)$ & $5(11.6)$ & 0.115 \\
\hline$E G F R$ mutation status, $n(\%)$ & & & 0.361 \\
\hline Group $1^{c}$ & $29(74.4)$ & $36(83.7)$ & \\
\hline
\end{tabular}

(Continued) 


\begin{tabular}{cccc}
\hline Characteristic & $\begin{array}{c}\text { Patients with BMs with } \\
\text { upfront local treatment }\end{array}$ & $\begin{array}{c}\text { Patients with BMs without } \\
\text { upfront local treatment }\end{array}$ & \multirow{P}{*}{-value } \\
\cline { 2 - 3 } & $(\boldsymbol{n}=\mathbf{3 9 )}$ & $(\boldsymbol{n}=\mathbf{4 3})$ \\
\hline Group 2 & $1(2.6)$ & $2(4.7)$ \\
Group 3 & $9(23.1)$ & $5(11.6)$ \\
\hline
\end{tabular}

${ }^{*} P<0.05$.

${ }^{a}$ Ceased smoking $>1$ year before diagnosis.

${ }^{\mathrm{b}}$ Significant weight loss of $>10.0 \%$ within 6 months of diagnosis.

${ }^{\mathrm{c}}$ Classical mutation(s).

${ }^{\mathrm{d} C}$ Complex mutation with classical mutation.

'Rare mutation with or without complex mutation.

BM, brain metastases; ECOG, Eastern Cooperative Oncology Group; EGFR, epidermal growth factor receptor; F, female; $\mathrm{M}$, male; PD, progressive disease; PS, performance status.

Table 4: Univariate and multivariate analyses of clinical factors for overall survival in a real-world cohort

\begin{tabular}{|c|c|c|c|c|c|}
\hline \multirow[t]{2}{*}{ Clinical factor } & \multirow[t]{2}{*}{ Patients $(n)$} & \multicolumn{2}{|c|}{ Univariate analysis } & \multicolumn{2}{|c|}{ Multivariate analysis } \\
\hline & & HR $(95.0 \%$ CI) & $P$-value & HR $(95.0 \%$ CI $)$ & $P$-value \\
\hline \multicolumn{6}{|l|}{ Sex } \\
\hline M & 102 & $1.33(0.81-2.20)$ & 0.26 & - & - \\
\hline $\mathrm{F}$ & 157 & 1 & & - & \\
\hline \multicolumn{6}{|l|}{ Smoking status } \\
\hline Never smoked & 187 & 1 & & - & \\
\hline Current or Ex-smoker & 72 & $1.52(0.91-2.56)$ & 0.112 & - & - \\
\hline \multicolumn{6}{|l|}{ ECOG PS } \\
\hline $0-1$ & 239 & 1 & & - & \\
\hline $2-4$ & 20 & $1.50(0.68-3.31)$ & 0.313 & - & - \\
\hline \multicolumn{6}{|l|}{$\mathrm{BMs}$} \\
\hline Present & 82 & $2.03(1.23-3.35)$ & $0.006^{*}$ & $1.97(1.19-3.26)$ & $0.008^{*}$ \\
\hline Absent & 177 & 1 & & 1 & \\
\hline \multicolumn{6}{|l|}{$E G F R$ mutation status } \\
\hline Group $1^{\mathrm{a}}$ & 207 & $0.58(0.36-1.00)$ & 0.05 & $0.59(0.34-1.02)$ & 0.06 \\
\hline Group 2-3 $3^{\mathrm{b}, \mathrm{c}}$ & 52 & 1 & & 1 & \\
\hline \multicolumn{6}{|c|}{ Tumor response to afatinib treatment } \\
\hline PR & 180 & $0.43(0.26-0.71)$ & $0.001^{*}$ & $0.47(0.28-0.77)$ & $0.003^{*}$ \\
\hline $\mathrm{SD} / \mathrm{PD}$ & 79 & 1 & & 1 & \\
\hline \multicolumn{6}{|c|}{ Afatinib dose during the first 6 months of treatment $(\mathrm{mg})$} \\
\hline 40 & 139 & $0.997(0.61-1.64)$ & 0.992 & - & - \\
\hline$<40$ & 120 & 1 & & - & \\
\hline $\begin{array}{l}{ }^{*} P<0.05 . \\
\text { a Classical mutation(s). } \\
\text { bComplex mutation with cl } \\
\text { }{ }^{\mathrm{c}} \text { Rare mutation with or wit } \\
\text { BM, brain metastasis; CI, } \\
\text { factor receptor; F, female; } \\
\text { SD, stable disease. }\end{array}$ & $\begin{array}{l}\text { al mutation. } \\
\text { complex mutat } \\
\text { lence interval; } \\
\text { lazard ratio; M }\end{array}$ & $\begin{array}{l}\text { astern Cooperative } \\
\text {, progressive dise }\end{array}$ & - & . & th \\
\hline
\end{tabular}


In clinical practice, oncologists and neurological surgeons prescribe upfront local therapy for patients presenting with any significant neurological symptoms, intracranial hemorrhage, and those with $>3 \mathrm{~cm}$ brain tumor on imaging studies. Although patients who received upfront local treatment initially had relatively poor PS, combined upfront local treatment and afatinib can provide a good median OS. A multi-institutional study in the United States also demonstrated that the use of upfront SRS or WBRT is associated with better OS (46 and 30 months, respectively) in patients with EGFR-mutant NSCLC with brain metastases compared to EGFR-TKI monotherapy [20]. A high cerebral efficacy of EGFRTKIs has been reported in recent studies, with high response rates of $70 \%$ to $80 \%$ in patients with $E G F R$ mutant NSCLC with CNS metastases [21-23]. However, the clinical efficacy of such drug in terms of intracranial responses can be confounded by the varying concentration of different TKIs in the cerebrospinal fluid (CSF) [24, 25]. WBRT might disrupt the blood-brain barrier, causing a favorable CNS response rate by increasing the CSF concentration in afatinib treatment. From this study, we used the analytic model of competing risk regression for investigating the cumulative incidence of CNS progression between patients receiving upfront local treatments for initial brain metastases and those did not receive upfront local treatments. Although, patients with any upfront local treatment prior to afatinib could have better OS (median 36.7 vs. 19.5 months, respectively) compared with those without upfront local treatments, the statistical difference was not significant (HR: 0.73; 95.0\% CI: 0.34-1.56; $P=0.409)$. Meanwhile, patients with brain metastases receiving any upfront local treatment prior to afatinib did not provide benefits in CNS progression (subhazard ratio: 1.16; 95.0\% CI: $0.54-2.50 ; P=0.70)$. The effectiveness and survival benefits of patients with upfront local treatments to brain metastases will need more clinical studies to clarify.

In conclusion, brain metastasis is associated with poor ECOG PS, high rate of CNS progression, and short OS. Brain metastases at the time of the diagnostic stage and the initial treatment response to afatinib are two important prognostic factors for the overall survival of first-line afatinib treated $E G F R$ mutation-positive lung adenocarcinoma.

\section{MATERIALS AND METHODS}

\section{Patients and data collection}

From May 2014 to June 2017, we subsequently retrieved data of patients with advanced EGFR mutationpositive lung adenocarcinoma receiving afatinib as a firstline therapy at the National Taiwan University Hospital (Taipei, Taiwan). We excluded patients (1) with unknown EGFR mutation status, (2) those in whom afatinib was discontinued and treatment was subsequent switched to other EGFR-TKIs prior to disease progression, and (3) those who received a combination of immunotherapy or palliative chemotherapy prior to afatinib treatment. This study had been approved by the Research Ethics Committee of the National Taiwan University Hospital (Taipei, Taiwan), and written informed consent was waived owing to the retrospective nature of the study.

Of the 282 screened patients, 23 patients were excluded because they received systemic therapy or immune checkpoint therapy concomitantly $(n=10)$ and afatinib was discontinued and then switched to other EGFR-TKI treatment due to various severe adverse events $(\mathrm{n}=13)$; including 5 severe skin rashes, 5 oral mucositis, 1 refractory diarrhea, 1 paronychia, and 1 interstitial pneumonitis. The clinical characteristics, imaging studies, and medical records of the 259 enrolled patients were consecutively collected until August 2017. Ex-smokers were defined as patients who quit smoking for $>1$ year at the time of lung cancer diagnosis. ECOG scale was used to determine the patients' PS [26]. All patients with stage IV lung adenocarcinoma [27] received afatinib as first-line treatment.

Tumor responses to afatinib were evaluated and recorded by primary care physicians according to the Response Evaluation Criteria in Solid Tumors (version 1.1) [28]. Imaging studies, including computed tomography of the chest and computed tomography/ magnetic resonance imaging of brain, were routinely followed up at a 3-month interval. PFS was defined as the period from starting afatinib treatment to the point of radiologically documented disease progression. OS was defined as the duration from commencing afatinib treatment to death from any cause.

The cutoff date for collecting clinical data ended on August 31, 2017. The median follow-up period was 22.0 (range, 2.0-40.0) months.

\section{Data on EGFR mutation status}

Data on the EGFR mutation status of patients were collected from formal pathology reports and referral data from other hospitals. Cancer specimens could be obtained from primary lung adenocarcinomas, tissues from metastatic sites, or malignant pleural effusion cell blocks.

\section{Statistical analysis}

In our study, categorical variables were compared using Pearson's chi-squared tests for. OS was calculated using the Kaplan-Meier method and compared using the log-rank test. We also used cumulative incidence risk to analyze the first events of CNS progression. Other first events of non-CNS progression, death or loss to followup beyond progression were analyzed as competing risks. HRs were used in Cox proportional hazard models, and 
the corresponding 95\% CIs were used to compare the OS between the treatment subgroups. The Statistical Package for the Social Sciences for Windows software version 18.0 (SPSS Inc., Chicago, IL, USA) were used for all statistical analyses. OS and cumulative incidence curves were plotted using STATA for Windows software version 14.0 (StataCorp, College station, TX, USA). A two-sided $P<0.05$ was considered statistically significant.

\section{Abbreviations}

CI, confidence interval; ECOG, Eastern Cooperative Oncology Group; EGFR-TKI, epidermal growth factor receptor-tyrosine kinase inhibitor; HR, hazard ratio; OS, overall survival; PFS, progression-free survival; PS, performance status.

\section{Author contributions}

S.-K.L. collected patients' information, analyzed data, and wrote the manuscript. M.-R.L. provided statistical support. J.-Y.S. designed the research and supervised the study. W.-Y.L. and C.-C.H. were the primary care physicians for majority of our enrolled patients, provided informative data, and revised the manuscript. J.-C.K. edited and revised the manuscript. All authors read and approved the final manuscript.

\section{ACKNOWLEDGMENTS}

We thank the National Taiwan University Hospital Hsinchu Branch (Hsinchu, Taiwan), National Taiwan University Hospital and College of Medicine, and the Office of Research and Development of the National Taiwan University (Taipei, Taiwan) for facility support.

\section{CONFLICTS OF INTEREST}

Sheng-Kai Liang has received honoraria for speeches from Roche, AstraZeneca, Pfizer, and Boehringer Ingelheim. Chao-Chi Ho has received grants from AstraZeneca (\#ISSIRES0105) and honoraria for speeches or participated in compensated advisory board of Boehringer Ingelheim, Eli Lilly, Roche/Genentech/Chugai, MSD, Pfizer, Novartis, BMS, and Ono pharmaceutical. Jen-Chung Ko has received honoraria for speeches from Roche, AstraZeneca, and Boehringer Ingelheim. Jin-Yuan Shih has received speaking honoraria from AstraZeneca, Roche, Boehringer Ingelheim, Eli Lilly, Pfizer, Novartis, Merck Sharp \& Dohme, Ono Pharmaceutical, and BristolMyers Squibb. All other authors have no conflicts of interest to declare.

\section{FUNDING}

None.

\section{REFERENCES}

1. Goldstraw P, Crowley J, Chansky K, Giroux DJ, Groome PA, Rami-Porta R, Postmus PE, Rusch V, Sobin L, and International Association for the Study of Lung Cancer International Staging Committee, and Participating Institutions. The IASLC Lung Cancer Staging Project: proposals for the revision of the TNM stage groupings in the forthcoming (seventh) edition of the TNM Classification of malignant tumours. J Thorac Oncol. 2007; 2:706-14. https://doi.org/10.1097/JTO.0b013e31812f3cla.

2. Goldstraw P, Chansky K, Crowley J, Rami-Porta R, Asamura H, Eberhardt WE, Nicholson AG, Groome P, Mitchell A, Bolejack V, Goldstraw P, Rami-Porta R, Asamura $\mathrm{H}$, et al, and International Association for the Study of Lung Cancer Staging and Prognostic Factors Committee, Advisory Boards, and Participating Institutions, and International Association for the Study of Lung Cancer Staging and Prognostic Factors Committee Advisory Boards and Participating Institutions. The IASLC lung cancer staging project: proposals for revision of the TNM stage groupings in the forthcoming (eighth) edition of the TNM classification for lung cancer. J Thorac Oncol. 2016; 11:3951. https://doi.org/10.1016/j.jtho.2015.09.009.

3. Albain KS, Crowley JJ, LeBlanc M, Livingston RB. Survival determinants in extensive-stage non-small-cell lung cancer: the Southwest Oncology Group experience. J Clin Oncol. 1991; 9:1618-26. https://doi.org/10.1200/ JCO.1991.9.9.1618.

4. Abbasi S, Badheeb A. Prognostic factors in advanced nonsmall-cell lung cancer patients: patient characteristics and type of chemotherapy. Lung Cancer Int. 2011; 2011:152125. https://doi.org/10.4061/2011/152125.

5. Nakamura H, Ando K, Shinmyo T, Morita K, Mochizuki A, Kurimoto N, Tatsunami S. Female gender is an independent prognostic factor in non-small-cell lung cancer: a metaanalysis. Ann Thorac Cardiovasc Surg. 2011; 17:469-80. https://doi.org/10.5761/atcs.oa.10.01637.

6. Asamura H, Kameya T, Matsuno Y, Noguchi M, Tada H, Ishikawa Y, Yokose T, Jiang SX, Inoue T, Nakagawa K, Tajima K, Nagai K. Neuroendocrine neoplasms of the lung: a prognostic spectrum. J Clin Oncol. 2006; 24:70-76. https://doi.org/10.1200/JCO.2005.04.1202.

7. Lynch TJ, Bell DW, Sordella R, Gurubhagavatula S, Okimoto RA, Brannigan BW, Harris PL, Haserlat SM, Supko JG, Haluska FG, Louis DN, Christiani DC, Settleman J, Haber DA. Activating mutations in the epidermal growth factor receptor underlying responsiveness of non-small-cell lung cancer to gefitinib. N Engl J Med. 2004; 350:2129-39. https://doi.org/10.1056/NEJMoa040938.

8. Sequist LV, Yang JC, Yamamoto N, O'Byrne K, Hirsh V, Mok T, Geater SL, Orlov S, Tsai CM, Boyer M, Su WC, Bennouna J, Kato T, et al. Phase III study of afatinib or cisplatin plus pemetrexed in patients with metastatic lung adenocarcinoma with EGFR mutations. J Clin Oncol. 2013; 31:3327-34. https://doi.org/10.1200/JCO.2012.44.2806. 
9. Wu YL, Zhou C, Hu CP, Feng J, Lu S, Huang Y, Li W, Hou M, Shi JH, Lee KY, Xu CR, Massey D, Kim M, et al. Afatinib versus cisplatin plus gemcitabine for firstline treatment of Asian patients with advanced nonsmall-cell lung cancer harbouring EGFR mutations (LUX-Lung 6): an open-label, randomised phase 3 trial. Lancet Oncol. 2014; 15:213-22. https://doi.org/10.1016/ S1470-2045(13)70604-1.

10. Park K, Tan EH, O’Byrne K, Zhang L, Boyer M, Mok T, Hirsh V, Yang JC, Lee KH, Lu S, Shi Y, Kim SW, Laskin $\mathrm{J}$, et al. Afatinib versus gefitinib as first-line treatment of patients with EGFR mutation-positive non-small-cell lung cancer (LUX-Lung 7): a phase 2B, open-label, randomised controlled trial. Lancet Oncol. 2016; 17:577-89. https://doi. org/10.1016/S1470-2045(16)30033-X.

11. Barnholtz-Sloan JS, Sloan AE, Davis FG, Vigneau FD, Lai $\mathrm{P}$, Sawaya RE. Incidence proportions of brain metastases in patients diagnosed (1973 to 2001) in the Metropolitan Detroit Cancer Surveillance System. J Clin Oncol. 2004; 22:2865-72. https://doi.org/10.1200/JCO.2004.12.149.

12. Nguyen T, Deangelis LM. Treatment of brain metastases. J Support Oncol. 2004; 2:405-10.

13. Iuchi T, Shingyoji M, Sakaida T, Hatano K, Nagano O, Itakura M, Kageyama H, Yokoi S, Hasegawa Y, Kawasaki $\mathrm{K}$, Iizasa T. Phase II trial of gefitinib alone without radiation therapy for Japanese patients with brain metastases from EGFR-mutant lung adenocarcinoma. Lung Cancer. 2013; 82:282-87. https://doi.org/10.1016/j.lungcan.2013.08.016.

14. Rosell R, Carcereny E, Gervais R, Vergnenegre A, Massuti B, Felip E, Palmero R, Garcia-Gomez R, Pallares C, Sanchez JM, Porta R, Cobo M, Garrido P, et al, and Spanish Lung Cancer Group in collaboration with Groupe Français de Pneumo-Cancérologie and Associazione Italiana Oncologia Toracica. Erlotinib versus standard chemotherapy as first-line treatment for European patients with advanced EGFR mutation-positive non-small-cell lung cancer (EURTAC): a multicentre, open-label, randomised phase 3 trial. Lancet Oncol. 2012; 13:239-46. https://doi. org/10.1016/S1470-2045(11)70393-X.

15. Schuler M, Wu YL, Hirsh V, O’Byrne K, Yamamoto N, Mok T, Popat S, Sequist LV, Massey D, Zazulina V, Yang JC. First-line afatinib versus chemotherapy in patients with non-small cell lung cancer and common epidermal growth factor receptor gene mutations and brain metastases. J Thorac Oncol. 2016; 11:380-90. https://doi.org/10.1016/j. jtho.2015.11.014.

16. Li MX, He H, Ruan ZH, Zhu YX, Li RQ, He X, Lan BH, Zhang ZM, Liu GD, Xiao HL, Wu Y, Zhu B, Wang G, Yang ZZ. Central nervous system progression in advanced non-small cell lung cancer patients with EGFR mutations in response to first-line treatment with two EGFR-TKIs, gefitinib and erlotinib: a comparative study. BMC Cancer. 2017; 17:245. https://doi.org/10.1186/s12885-017-3165-0.

17. Gaspar LE, Mehta MP, Patchell RA, Burri SH, Robinson PD, Morris RE, Ammirati M, Andrews DW, Asher AL,
Cobbs CS, Kondziolka D, Linskey ME, Loeffler JS, et al. The role of whole brain radiation therapy in the management of newly diagnosed brain metastases: a systematic review and evidence-based clinical practice guideline. J Neurooncol. 2010; 96:17-32. https://doi. org/10.1007/s11060-009-0060-9.

18. Ettinger DS, Wood DE, Aisner DL, Akerley W, Bauman J, Chirieac LR, D'Amico TA, DeCamp MM, Dilling TJ, Dobelbower M, Doebele RC, Govindan R, Gubens MA, et al. Non-small cell lung cancer, version 5.2017, NCCN clinical practice guidelines in oncology. J Natl Compr Canc Netw. 2017; 15:504-35. https://doi.org/10.6004/ jncen.2017.0050.

19. Liang SK, Hsieh MS, Lee MR, Keng LT, Ko JC, Shih JY. Real-world experience of afatinib as a first-line therapy for advanced EGFR mutation-positive lung adenocarcinoma. Oncotarget. 2017; 8:90430-43. https://doi.org/10.18632/ oncotarget.19563.

20. Magnuson WJ, Lester-Coll NH, Wu AJ, Yang TJ, Lockney NA, Gerber NK, Beal K, Amini A, Patil T, Kavanagh BD, Camidge DR, Braunstein SE, Boreta LC, et al. Management of brain metastases in tyrosine kinase inhibitor-naive epidermal growth factor receptor-mutant non-small-cell lung cancer: a retrospective multi-institutional analysis. J Clin Oncol. 2017; 35:1070-77. https://doi.org/10.1200/ JCO.2016.69.7144.

21. Berger LA, Riesenberg H, Bokemeyer C, Atanackovic D. CNS metastases in non-small-cell lung cancer: current role of EGFR-TKI therapy and future perspectives. Lung Cancer. 2013; 80:242-48. https://doi.org/10.1016/j. lungcan.2013.02.004.

22. Ballard P, Yates JW, Yang Z, Kim DW, Yang JC, Cantarini M, Pickup K, Jordan A, Hickey M, Grist M, Box M, Johnström P, Varnäs K, et al. Preclinical comparison of osimertinib with other EGFR-TKIs in EGFR-mutant NSCLC brain metastases models, and early evidence of clinical brain metastases activity. Clin Cancer Res. 2016; 22:5130-40. https://doi.org/10.1158/1078-0432. CCR-16-0399.

23. Wind S, Schmid M, Erhardt J, Goeldner RG, Stopfer P. Pharmacokinetics of afatinib, a selective irreversible ErbB family blocker, in patients with advanced solid tumours. Clin Pharmacokinet. 2013; 52:1101-09. https://doi. org/10.1007/s40262-013-0091-4.

24. Hoffknecht P, Tufman A, Wehler T, Pelzer T, Wiewrodt R, Schütz M, Serke M, Stöhlmacher-Williams J, Märten A, Maria Huber R, Dickgreber NJ, and Afatinib Compassionate Use Consortium (ACUC). Efficacy of the irreversible ErbB family blocker afatinib in epidermal growth factor receptor (EGFR) tyrosine kinase inhibitor (TKI)-pretreated nonsmall-cell lung cancer patients with brain metastases or leptomeningeal disease. J Thorac Oncol. 2015; 10:156-63. https://doi.org/10.1097/JTO.0000000000000380.

25. Togashi Y, Masago K, Masuda S, Mizuno T, Fukudo M, Ikemi Y, Sakamori Y, Nagai H, Kim YH, Katsura T, 
Mishima M. Cerebrospinal fluid concentration of gefitinib and erlotinib in patients with non-small cell lung cancer. Cancer Chemother Pharmacol. 2012; 70:399-405. https:// doi.org/10.1007/s00280-012-1929-4.

26. Oken MM, Creech RH, Tormey DC, Horton J, Davis TE, McFadden ET, Carbone PP. Toxicity and response criteria of the Eastern Cooperative Oncology Group. Am J Clin Oncol. 1982; 5:649-55. https://doi. org/10.1097/00000421-198212000-00014.

27. Edge SB, Compton CC. The american joint committee on cancer: the 7th edition of the AJCC cancer staging manual and the future of TNM. Annals of surgical oncology. 2010; 17:1471-4.

28. Eisenhauer EA, Therasse P, Bogaerts J, Schwartz LH, Sargent D, Ford R, Dancey J, Arbuck S, Gwyther S, Mooney M, Rubinstein L, Shankar L, Dodd L, et al. New response evaluation criteria in solid tumours: revised RECIST guideline (version 1.1). Eur J Cancer. 2009; 45:228-47. https://doi.org/10.1016/j.ejca.2008.10.026. 